\title{
Suicide highlights graduate student woes
}

[вОSTON] Harvard University is reviewing its policies on graduate students following the death of Jason Altom, a fifth-year PhD candidate in the chemistry department who killed himself last August by taking cyanide.

Altom, the third Harvard graduate student to commit suicide since 1997, was working on the synthesis of a complex molecule under the supervision of organic chemist Elias J. Corey, winner of the 1990 Nobel prize.

"This event could have been avoided," Altom wrote in a suicide note, part of which was reprinted by the Harvard Crimson, a student newspaper. "Professors have too much power over the lives of their grad students."

Altom suggested in the note that a thesis committee, made up of three professors, should be formed earlier in the research process to help students assess their work and to protect them from what he described as "abusive research advisers". He added: "If I had such a committee now, I know things would be different."

Poor faculty advising had been highlighted last March as a serious problem in a letter to the university administration from the Graduate Student Council. Changes in the advising structure, as advocated by Altom and the student council, were incorporated in a nine-point plan adopted by the chemistry department in mid-September.

"Jason's death prompted an examination of the role the department should play in graduate students' lives," says atmospheric chemist James Anderson, who became department chairman in July.

Under the new guidelines, each secondyear graduate student will establish a prethesis committee composed of the adviser and two other faculty members. Students will also have "confidential and seamless access" to psychological counselling services paid for by the department, says Anderson.

Other changes include the introduction of "frequent" buffet dinners for graduate students, postdocs and faculty members, as well as regular meetings between the chairman and graduate school classes.

A survey will assess the usefulness of the new policies. "We plan to make more changes, but want to evaluate these measures first," says Anderson. The heads of Harvard's other science departments are "paying close attention to what we're doing", he adds. "They realize that the isolation and depression experienced by some graduate students is not unique to chemistry."

All 3,400 of Harvard's graduate students were questioned during the registration period in September about the effectiveness of the advisory system. "Our efforts have been galvanized by this event [Altom's suicide]," says Margot Gill, administrative dean of the graduate school. "It has forced us to ask if there is more we can do to improve the graduate student experience."

Anne Pruitt-Logan, scholar in residence at the Council of Graduate Schools in Washington DC, endorses the idea of creating advisory committees for students. "But most of these committees focus too narrowly on the research, when students need broader mentoring," she says.

Although the advisers would not be counsellors per se, says Pruitt-Logan, "they would hopefully be observant enough to see that something is amiss. Having a group of advisers increases the chances that someone will catch signs of distress."

Stephen Senturia, an electrical engineering professor at the Massachusetts Institute of Technology (MIT), agrees that the adviser-student relationship is a critical issue. "It's easy to fall into the notion that the adviser owns your life," says Senturia, who runs workshops that expose students to ethical dilemmas in research and train them to handle problems with their supervisors.

Thesis committees at the university should form earlier than they do at present, he suggests, as a way of "broadening the support base for students".

But Senturia points out that MIT's Graduate Student Council is not pushing for changes in the advisory programme. That could mean that students are satisfied with the present system, he says. "Or maybe they're just too busy." SteveNadis

\section{Damaged satellite adds to delays facing $X$-ray astronomers}

[MUNICH] The German X-ray satellite ROSAT, which has been operating for more than four times longer than planned, may have to be abandoned after it was accidentally pointed towards the Sun.

The accident resulted in damage to one of its three main instruments, the highresolution imager (HRI), developed at the Smithsonian Astronomical Observatory in Cambridge, Massachusetts. As a result, the latest call for research proposals, whose deadline was next month, has been put on ice as scientists attempt to determine the extent of the damage and assess whether a rescue is possible.

If not, the satellite's operation will not overlap with two new major X-ray astronomy missions, NASA's Advanced XRay Astrophysics Facility (AXAF) and the European Space Agency's XMM. An overlap would have kept new data flowing to the $\mathrm{X}$ ray astronomy community without a break

ROSAT was launched in summer 1990, with an intended lifespan of 20 months. One of its main goals was to carry out an all-sky survey of X-ray sources, and a catalogue of

such sources was published by the Max Planck Institute for Extraterrestrial Physics in Garching, Germany, in 1996.

As well as the HRI, ROSAT's other main instruments are a Position Sensitive Proportional Counter and a Wide Field Camera. After the satellite's positioning system failed last April, attempts were made to adapt the Wide Field Camera, developed at Britain's University of Leicester, to take over the control function. But a chain of events resulted in loss of positional control during a test at the end of September. ROSAT scientists say there is little hope of reviving the HRI. Funding for the satellite's operation has been guaranteed by the German ministry of research until the end of 1999, but none of ROSAT's instruments is likely to be usable for that long.

One consequence of the technical problems is that the life of the third main instrument, the Positional Sensitive Proportion Counter, has been reduced to a few days. This instrument measures both the position and energy of $\mathrm{X}$-ray sources, and was developed at the Max Planck Institute for Extraterrestrial Physics.

The Wide Field Camera has already completed most of the viewing within its technical capability, says Martin Ward, director of the University of Leicester's X-Ray Astronomy Group.

But X-ray astronomers are facing additional disappointments. The launch of AXAF, originally planned for last August, was delayed until next January following technical problems, and last week a further delay of several months was announced. XMM has been delayed for six months, until February 2000 (see Nature 395, 732; 1998).

Ward says that, although the likely loss of ROSAT is unfortunate, there are still opportunities for X-ray astronomers to do new work, for example with the Italian mission SAX, launched in 1996.

Joachim Trümper, the director of the ROSAT project, is disappointed but pragmatic. "We expected two years," he says, "so with a happy and fruitful life of eight years we can't complain. We knew it would have to end sometime."

Alison Abbott 